\title{
Point of care coagulation tests do not reduce requirements for allogeneic blood transfusions during and after cardiac surgery
}

\section{Kodaka M, Ichikawa J, Nihei W, Nishiyama K, Komori M. Department of Anaesthesia and Intensive care, Tokyo Women's Medical University Medical Centre East}

Background and Goal of Study

A previous retrospective study showed that point of care (POC) coagulation tests reduce the requirements for hemostatic products and shorten hospital stay. ${ }^{1}$ However, few prospective studies have provided evidence that POC coagulation tests have this effect in patients undergoing cardiac surgery. ${ }^{2}$ The current investigation aimed to use logistic regression analysis to assess the efficacy of hemostatic therapy guided either by conventional coagulation analyses or POC, such as ROTEM ${ }^{\mathrm{TM}}$ and Hepcon $\mathrm{HMS}^{\mathrm{TM}}$.

\section{Material and Methods}

Patients scheduled for cardiac surgery with cardiopulmonary bypass (CPB) were randomized to a conventional (Control) or POC group.

The criteria for Control were as follows: by $C B C($ Complete blood counts), such as.

hemoglobin $(\mathrm{Hb})>9-10 \mathrm{mg} / \mathrm{dL}$, fibrinogen $(\mathrm{Fib})>100-150 \mathrm{mg} / \mathrm{dL}$, platelet count (PIt) $>5-10 \times 10^{4} / \mu \mathrm{L}$. A heparin dose of $300-400 \mathrm{U} / \mathrm{kg}$ was administered during CPB, the target ACT $>450 \mathrm{sec}$ (Hemocron Signature), and reversed with protamine $50-130 \%$ of heparin.

ROTEM $^{\mathrm{TM}}$ and $\mathrm{HMS}^{\mathrm{TM}}$ were performed in the POC group.

Hemostatic therapy comprised red blood cells (RBCs), fresh frozen plasma (FFP), and concentrated platelets (PC).

Samples were collected at four points:

$1^{\text {st }}$. Baseline,

$2^{\text {nd }} . J u s t$ after starting $\mathrm{CPB}$,

$3^{\text {rd }}$. During weaning from $\mathrm{CPB}$,

$4^{\text {th }}$. At the end of surgery.

For control group, we referred to " $2^{\text {nd }}$ point" of CBC and Fib.

For POC group, we did to "3rd point" of ROTEM.

The primary outcome variables were the number of transfused units and blood loss during operation and the first $48 \mathrm{~h}$ after ICU. Secondary outcomes were results of multiple logistic regression analysis in which the dependent variable was with or without allogeneic blood transfusion and independent variables included groups, $\mathrm{Hb}$, Fib, Plt, and age.

\section{Table 1: Patients characteristics}

\begin{tabular}{|c|c|c|c|}
\hline & Control $(n=30)$ & $\operatorname{POC}(n=30)$ & $p$-value \\
\hline Age (y/o) & $68 \pm 9$ & $72 \pm 7$ & 0.07 \\
\hline Gender（M:F） & $18: 12$ & $21: 9$ & 0.42 \\
\hline Height $(\mathrm{cm})$ & $160 \pm 8$ & $160 \pm 9$ & 0.87 \\
\hline Weight（kg） & $58 \pm 10$ & $59 \pm 12$ & 0.62 \\
\hline Operative methods & & & 0.13 \\
\hline Coronary bypass & 1 & 1 & \\
\hline Single valve repair/replace & 12 & 21 & \\
\hline Double valve repair/replace & 7 & 3 & \\
\hline Triple valve repair/replace & 0 & 0 & \\
\hline Single valve+bypass & 5 & 1 & \\
\hline Double valve+bypass & 1 & 0 & \\
\hline Aortic replace & 4 & 4 & \\
\hline Anaesthesia (min) & $353 \pm 110$ & $346 \pm 118$ & 0.79 \\
\hline Surgery (min) & $294 \pm 107$ & $289 \pm 113$ & 0.83 \\
\hline Cardio-pulmonary bypass ( $\min )$ & $148 \pm 57$ & $134 \pm 60$ & 0.35 \\
\hline
\end{tabular}

Results

Sixty patients were enrolled in the study. Patients characteristics was indicated at Table 1.

Table 2 also indicated that there were no significant differences in blood transfusion and perioperative bleeding between the groups The secondary outcomes shown in Table 3 were that only $\mathrm{Hb}-2^{\text {nd }}$, Plt- $1^{\text {st }}$, and age were independent factors to determine blood transfusion. The other perioperative outcomes including respiratory $\mathrm{P} / \mathrm{F}$ ratio, $\mathrm{CBC}$, coagulation test, and ROTEM data suggested no difference between the groups as well (data weren't shown).
Table 2 : Peri-operative transfusion and bleeding

\begin{tabular}{|c|c|c|c|c|}
\hline & & Control $(n=30)$ & $\operatorname{POC}(n=30)$ & $P$ value \\
\hline \multirow[t]{4}{*}{ In the OR: } & RBCs（units） & $5.5 \pm 4.6$ & $4.2 \pm 3.7$ & 0.25 \\
\hline & FFP（units） & $2.1 \pm 3.9$ & $2.5 \pm 4.4$ & 0.71 \\
\hline & PC (units) & $3.2 \pm 2.3$ & $2.3 \pm 6.3$ & 0.61 \\
\hline & Bleeding（g） & $633 \pm 750$ & $586 \pm 607$ & 0.80 \\
\hline \multicolumn{2}{|c|}{ Allogeneic transfusion (\%) } & 60 & 70 & 0.42 \\
\hline \multirow[t]{5}{*}{ In the ICU: } & RBCs（units） & $1.2 \pm 2.2$ & $0.9 \pm 1.8$ & 0.52 \\
\hline & FFP（units） & $0.3 \pm 1.0$ & $0.1 \pm 0.8$ & 0.61 \\
\hline & PC (units) & $0.7 \pm 3.7$ & $1.3 \pm 5.1$ & 0.56 \\
\hline & eding in $48 \mathrm{~h}(\mathrm{ml})$ & $562 \pm 263$ & $486 \pm 301$ & 0.30 \\
\hline & c transfusion (\%) & 30 & 27 & 0.77 \\
\hline \multicolumn{2}{|c|}{ ICU periods（days） } & $2.4 \pm 1.3$ & $5.2 \pm 11.7$ & 0.19 \\
\hline \multicolumn{2}{|c|}{ Hospitalization（days） } & $20.5 \pm 20.6$ & $19.7 \pm 25.0$ & 0.89 \\
\hline
\end{tabular}

RBCs: Red Blood Cells, FFP: Fresh Frozen Plasma, PC: Platelet Concentrate

Table3: Multiple logistic analysis

\begin{tabular}{|c|c|c|c|c|c|c|}
\hline & \multirow[b]{2}{*}{ B } & \multirow[b]{2}{*}{ SE } & \multirow[b]{2}{*}{ OR } & \multicolumn{2}{|c|}{$95 \%$ CI of OR } & \multirow[b]{2}{*}{$P$-value } \\
\hline & & & & Lower & Upper & \\
\hline POC (+) & 0.43 & 1.21 & 1.53 & 0.14 & 16.39 & 0.72 \\
\hline Age* & 0.29 & 0.13 & 1.35 & 1.04 & 1.76 & $0.03 *$ \\
\hline $\mathbf{H b} \mathbf{1}^{\text {st }}$ & -0.61 & 0.69 & 0.54 & 0.14 & 2.11 & 0.38 \\
\hline $\mathbf{H b}-2^{\mathrm{nd} *}$ & -2.5 & 1.22 & 0.08 & 0.01 & 0.87 & $0.04 *$ \\
\hline $\mathrm{Hb}-3^{\text {rd }}$ & 3.67 & 1.93 & 39.33 & 0.9 & 1722.42 & 0.06 \\
\hline Plt-1 ${ }^{\text {st }}{ }_{*}$ & -1.04 & 0.53 & 0.35 & 0.12 & 0.99 & $0.049 *$ \\
\hline PIt-2 ${ }^{\text {nd }}$ & 1.55 & 0.86 & 4.72 & 0.87 & 25.67 & 0.07 \\
\hline Plt-3 $3^{\text {rd }}$ & -0.82 & 0.5 & 0.44 & 0.16 & 1.19 & 0.1 \\
\hline Filb-1 $1^{\text {st }}$ & -0.001 & 0.01 & 0.99 & 0.97 & 1.02 & 0.9 \\
\hline Filb-2 $2^{\text {nd }}$ & 0.05 & 0.06 & 1.05 & 0.92 & 1.19 & 0.47 \\
\hline Filb-3 ${ }^{\text {rd }}$ & -0.04 & 0.05 & 0.96 & 0.87 & 1.06 & 0.41 \\
\hline
\end{tabular}

POC: Point of Care (ROTEM and HMS), B:Regression coeficient, SE: Standard Error, OR=Odds ratio, CI: Confidential Interval, Hb: Hemoglobin, PIt: Platelet count, Fib: Fibrinogen. $1^{\text {st }}$ : Baseline, $2^{\text {nd }}:$ CPB start, $3^{\text {rd }}:$ CPB end. $* P<0.05$.

Discussion

1. The main causes of decreasing of Fib and PIt during CPB were due to dilution and absorption occurred within one second of CPB starting ${ }^{3}$.

2. After that, those values were almost the same until the end CPB (figure). ${ }^{4}$

3. If ROTEM ${ }^{T M}$ is measured at weaning time, FFP dissolution will be in time enough.

4. The measurement of Fib and CBC usually needs $0.5-1$ hour, therefore, FFP dissolution tend to be late if checked at weaning time.

5. The fact (Fib and PIt decrease at the beginning of CPB and keep same level) may be useful for preparation of FFP and PC even if we can use only conventional measurement (control).
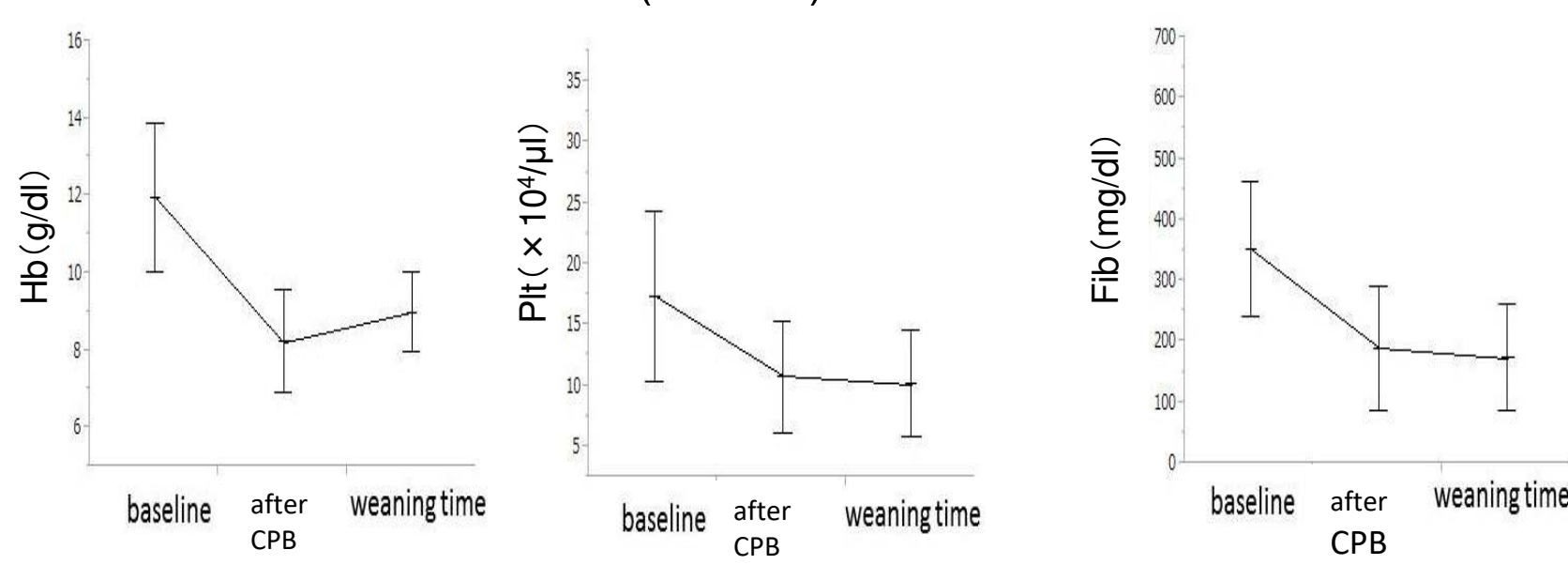

Figure $^{4}: \mathrm{Hb}$, Plt, and, Fib were significantly decreased just after CPB starting compared with baseline, the drop rate of $\mathrm{Hb}$, Plt, and Fib were $69,62,53 \%$ respectively $(p<0.0001)$. And Plt and Fib remained at the same level by the end of CPB.

\section{Conclusions}

Hemostatic therapy based on POC does not reduce patient requirements for allogenic blood products and bleeding during and after cardiac surgery.

\section{Acknowledgment}

The research was supported by JSPS KAKEN\#26462374.

References

1. Masui. 2015;64:131-8

2. Anesthesiology. $2011 ; 115: 1179-912$.

3. Thromb Haemost 1982:47:285

4. ASA annual meeting 22.Oct. 2016, A1072 